\title{
Avian influenza \\ The political economy of disease control in Cambodia
}

\author{
Sophal Ear \\ Department of National Security Affairs \\ U.S. Naval Postgraduate School \\ 1411 Cunningham Road \\ Monterey, CA 93943 \\ sear@nps.edu
}

\begin{abstract}
AвSTRACT. In the wake of avian flu outbreaks in 2004, Cambodia received $\$ 45$ million in commitments from international donors to help combat the spread of animal and human influenza, particularly avian influenza (H5N1). How countries leverage foreign aid to address the specific needs of donors and the endemic needs of the nation is a complex and nuanced issue throughout the developing world. Cambodia is a particularly compelling study in pandemic preparedness and the management of avian influenza because of its multilayered network of competing local, national, and global needs, and because the level of aid in Cambodia represents approximately \$2.65 million per human case-a disproportionately high number when compared with neighbors Vietnam and Indonesia. This paper examines how the Cambodian government has made use of animal and human influenza funds to protect (or fail to protect) its citizens and the global community. It asks how effective donor and government responses were to combating avian influenza in Cambodia, and what improvements could be made at the local and international level to help prepare for and respond to future outbreaks. Based on original interviews, a field survey of policy stakeholders, and detailed examination of Cambodia's health infrastructure and policies, the findings illustrate that while pandemic preparedness has shown improvements since 2004, new outbreaks and human fatalities accelerated in 2011, and more work needs to be done to align the specific goals of funders with the endemic needs of developing nations.
\end{abstract}

Key words: highly pathogenic avian influenza (HPAI), H5N1, Cambodia, political economy, disease control, Southeast Asia

$\mathrm{I}$ n 2003, outbreaks of avian influenza (Influenza A, subtype H5N1) in China and Vietnam prompted a global public health crisis. The response of individual nations varied widely depending on their resources, health infrastructure, and internal politics. At one extreme, China's government was criticized for its hesitancy to share data on and samples of $\mathrm{H} 5 \mathrm{~N} 1^{1}$ while other countries, such as Thailand, were more open to sharing information. In Cambodia, avian influenza was discovered in January 2004 on a poultry farm outside Phnom Penh. The country's experience with avian influenza provides an example of how a developing nation with limited resources and capabil-

doi: 10.2990/30_2_2

ities responds to a crisis with global public health implications and how the global response in turn affected Cambodia.

How countries make use of foreign aid to address endemic needs as well as the needs of donors and funding agencies is an important issue throughout the developing world. This paper focuses on Cambodia as a particularly compelling study in pandemic preparedness and the management of avian influenza. The country's multilayered network of competing local, national, and global actors, and the high level of aid it receivesrepresenting approximately $\$ 2.65$ million per human case, a disproportionately high number when compared with neighbors Vietnam and Indonesia-make Cambodia an important example. Research conducted for this 
paper examines how the Cambodian government has made use of animal and human influenza funds to protect (or fail to protect) its citizens and the global community.

The discovery of Cambodia's first confirmed human case occurred not in Cambodia at all, but Vietnam. News accounts were widely critical of Cambodia's notoriously weak health infrastructure. Indeed, a February 18, 2005 article in Science, titled "First Human Case in Cambodia Highlights Surveillance Shortcomings," warned that "the diagnosis was made not in Cambodia but in neighboring Vietnam, where [a] 25-year-old woman had sought treatment and died on 30 January." The article noted that "the woman's 14-year-old brother had died earlier of an apparent respiratory disease now suspected to be $\mathrm{H} 5 \mathrm{~N} 1$, but his remains were cremated before any samples were taken." $" 2$ Not only had Cambodia failed to detect its first human case but crucial evidence of possible spread had been destroyed. A March 5, 2005, Wall Street Journal report that appeared a few weeks later provided insight into the challenges facing the Cambodian government's response to avian influenza. The article praised Cambodia's "chief flu hunter at the cash-strapped Ministry of Health" but pointed out that Cambodia's entire "emergency budget for educating [the nation's] 13 million people about bird-flu dangers is just $\$ 2,500 ., 3$

Already awash in donor money-between 1995 and 2009, international aid comprised 10 percent of the country's Gross National Income ${ }^{4}$-Cambodia requested $\$ 32.5$ million from donors at the January 2006, International Pledging Conference on Avian and Human Influenza in Beijing. ${ }^{5}$ This request generated at least 15 implementing partners who committed \$22 million for 2008-2009 to combat avian influenza and promote preparedness across four areas: animal health, human health, information, education, and communication; and 4) pandemic preparedness. As of 2010, total commitments to Cambodia for avian influenza totaled $\$ 45$ million and, as of a July 2010 report by the United Nations and World Bank, \$34 million had been disbursed. ${ }^{6}$

The list of donors included the United Statessignificant because the U.S. had previously barred direct government-to-government support for Cambodia following the violence of July 5-6, 1997, during which the country's first Prime Minister, Prince
Norodom Ranariddh, was deposed. U.S. concern regarding the avian influenza pandemic was significant enough that an exception was allowed for the U.S. Centers for Disease Control and Prevention to work directly with the government of Cambodia on avian influenza preparedness and prevention. Throughout this crisis, the U.S. government has cooperated with a wide range of nations it does not have diplomatic relations with, including Burma, on issues of $\mathrm{H} 5 \mathrm{~N} 1$ preparedness. $^{7}$

Cambodia now ranks as one of the top 10 recipients worldwide of avian influenza funding commitments in absolute and relative terms (i.e., per case and per outbreak) according to the most recent available funding data, despite its relatively small number of human cases. As of August 2011, Cambodia has had a total of 17 human cases of H5N1, only two of whom survived. These two survivors were discovered during sentinel testing and surveillance by the Naval Area Medical Research Unit (NAMRU)-2, a U.S. Naval team charged with studying infectious diseases of public health importance to the United States and other regional partners. Although the official number of human cases in Cambodia stands at 17, many more cases may have existed. Avian influenza, and H5N1 in particular, is known to be vastly underreported, and there are likely a number of individuals who may have been exposed but are asymptomatic.

Proportionally, Cambodia's funding far outweighs that of other countries. Egypt, with 151 human cases, saw commitments of only $\$ 238,411$ per human case. Vietnam and Indonesia, which had 119 and 178 human cases respectively, saw pledges of approximately $\$ 1$ million per case. Thailand has suffered 25 cases (of which 17 resulted in deaths) but is not among the top recipients of animal and human influenza funding. Indeed, the UN and World Bank report makes no reference to Thailand receiving any animal and human influenza funding at all, although the U.S. Armed Forces Research Institute of Medical Sciences and the CDC Global Disease Detection Regional Center in Bangkok are said to have provided direct funding for avian influenza prevention. In light of the substantial sums of donor aid that have been directed at the Cambodian government to advance preparedness and prevention strategies, several key questions arise about disease control in a poor, aid-dependent country thought by some to be a potential birthplace of the 
next killer virus: 1) What did donors and government authorities know about the avian influenza epidemic, what was their response, and why? 2) How effective were donor and government responses to avian influenza in Cambodia? And, 3) what improvements can be made at the local and international level to help prepare for and respond to future outbreaks?

Using original interviews, a survey, and detailed examination of Cambodia's health infrastructure and policies, the study hypothesizes that a barrage of donors and NGOs would encircle the aid-dependent government, which would in turn mediate disease control activities through access to foreign aid. Such disease control would include behavior modification efforts, particularly in the areas of biosecurity and prevention of animal-to-human transmission, but not compensation for culling poultry (the political economy of which is discussed later). The study shows how Cambodia addressed (and failed to address) the threat of avian influenza and its impact on the Cambodian economy, its people, and the larger international community. It also offers a brief comparative analysis of the ways nearby Southeast Asian countries, namely Thailand, Indonesia, and Vietnam, managed international efforts to curb avian influenza domestically. Also examined are the complex issues surrounding Cambodia's attempts to leverage donor funds in a way that secured the safety of its citizens while meeting the needs of donor organizations, including the U.S. Agency for International Development, the International Federation of the Red Cross, and implementing partners such as the World Health Organization and Food and Agriculture Organization of the U.N., among others. For much of the 1990s and early 2000s, as a post-conflict and least developed country, Cambodia received foreign aid equivalent to half its government budget. But the needs of developing nations are not always aligned with the desires of donor organizations.

\section{Research design}

This paper uses a qualitative research methodology primarily consisting of one-on-one, semi-structured, original interviews with key stakeholders across government, nongovernmental (i.e., nonprofit), and private sectors. Interviewees included, but were not limited to, government officials, representatives of donor and nongovernmental organizations, private sector conglomerates, farmers, wet market (where live animals are sold) stall holders, and civil society representatives. These interviews were conducted over the course of three separate visits to Cambodia in February, May, and June of 2008.

A total of 49 face-to-face interviews were conducted in Khmer, French, and English, primarily in Phnom Penh and nearby environs, including one site visit to the coastal province of Kampong Som. A visit to Psah Orussey's wet market was also made to gain an appreciation for on-the-ground conditions. The author was not warmly received when photographing the wet market and was sternly warned by a seller "not to spread false stories in newspapers." Interviews lasted anywhere from 45 minutes to several hours (typically over the course of a meal).

Interviews were conducted with officials from numerous high-profile governmental and donor organizations, including among others the Ministry of Health's Communicable Diseases Control Department, which is in charge of surveillance of human diseases; the U.S. Agency for International Development (USAID), which was able to fund a number of activities in 2005 with leftover (unspent) funds that had previously been allocated to the December 26, 2004, Indian Ocean earthquake and tsunami; the U.S. Centers for Disease Control and Prevention (US-CDC), which works with the Ministry of Health by providing technical assistance to strengthen public health capacity to respond to HIV/ AIDS, avian influenza, and other public health priorities; and the Ministry of Agriculture, Forestry, and Fisheries, which performs veterinary epidemiological and diagnostic services within the Department of Animal Health and Production through the National Veterinary Research Institute. A list of interviewees, identified by role, is shown in Appendix 1.

In addition to face-to-face interviews, a confidential elite survey was sent via e-mail on May 27, 2008, to individuals involved in avian influenza work in Cambodia. (In contrast to a large household or population-based survey, an elite survey samples a smaller group of experts, including policymakers, opinion leaders, and other individuals directly engaged in the work or issue at hand.) The questionnaire focused on perceptions of effectiveness of the avian influenza response by the Cambodian government and donors who were working within Cambodia. The 
survey asked respondents to rate a series of symmetric statements asking whether the government, nongovernmental organizations, or donor agencies had intervened effectively and appropriately, given resource allocations. Five target dimensions were evaluated: (a) prevention among humans; (b) prevention among animals; (c) livelihood protection; (d) pandemic preparedness; (e) and an open-ended "other" category for which written comments were requested. The results offer a glimpse into stakeholder perceptions of government and donor effectiveness in intervening against avian influenza to protect animals, humans, livelihoods, and encourage pandemic preparedness.

Of the 17 respondents who completed the elite survey, 10 individuals had 1-3 years experience with the issue, 4 individuals had 4-6 months experience, and 3 individuals had less than three months experience working on avian influenza in Cambodia. The capacity in which these individuals worked on avian influenza ranged widely because cross-listing was permitted: human health ( 24 percent); animal health (16 percent); disaster management (24 percent); wildlife ( 8 percent); livelihoods (4 percent); and "other" (24 percent). The "other" category included six written responses addressing: (1) risk reduction and capacity building at the village level (animal and human health); (2) combining animal health with the impact on livelihoods; (3) U.N. agency (identifying themselves on the basis of their employer more so than a particular expertise); (4) communication for transmission risk reduction; (5) communication in general; and (6) animal and human influenza coordination incorporating all of the above. Survey respondents were primarily from donor agencies or foreign governments (65 percent); to a much lesser extent, they also represented the international NGO community (24 percent), for-profit private corporations (6 percent), and "other" (12 percent).

\section{Why Cambodia?}

The Fifth Global Progress Report, jointly published by the U.N. and World Bank in July 2010, entitled Animal and Pandemic Influenza: A Framework for Sustaining Momentum, reported that Cambodia ranked seventh among the top 10 countries and territories in receiving donor aid to combat avian influenza. Specifically, Cambodia received $\$ 45$ million in commitments (see Table 1).
In terms of commitments per capita, Cambodia ranked third, behind only Laos and Mexico (the latter of which represents a special case as the epicenter of H1N1 Swine Flu in 2009). In terms of commitments per outbreak, Cambodia ranked second only to Laos. With respect to commitments per human cases and human deaths, Cambodia ranked fifth and fourth, respectively. Moreover, the country relies heavily on donors-in the recent past, more than half of the country's budget came from foreign aid-making it an important case study for aid effectiveness.

\section{The risks of avian influenza}

Cambodia's vulnerability to avian influenza stems primarily from its reliance on backyard poultry farming. Cambodia does not export poultry or poultry products. Of the approximately 16 million poultry animals in Cambodia, 90 percent of these are backyard chickens and ducks. However, the interests of poor people who depend on poultry for their livelihood are not necessarily aligned with the interests of the Cambodian government, which is primarily concerned with protecting local and national business interests; neither of these interests lines up with the concerns of donors, who are primarily concerned with preventing the global spread of avian influenza.

In a 2008 online consultation sponsored by the Food and Agriculture Organization (FAO) of the United Nations on the reduction of the risk of highly pathogenic avian influenza (HPAI) and the reduction of poverty, Otte and Roland-Holst introduced a typology identifying four distinct risks to HPAI at the national and international levels. Their typology serves to highlight the difficulties found in Cambodia (see Table 2). As Otte and Roland-Holst explained during the e-consultation:

Let's face it - "Risk IV" is driving the international response while 'Risk III' is driving national responses where they occur to any significant measure. On the other hand, we also have to admit that "Risk I" is nothing that poor poultry producers would rate very high - the likelihood of their poultry dying from HPAI is much lower than that of dying from a plethora of other causes. Likewise, "Risk II" is also not something we can expect to be very high on the priority list of poor poultry keepers as they, like their chickens, are much more 


\section{Ear}

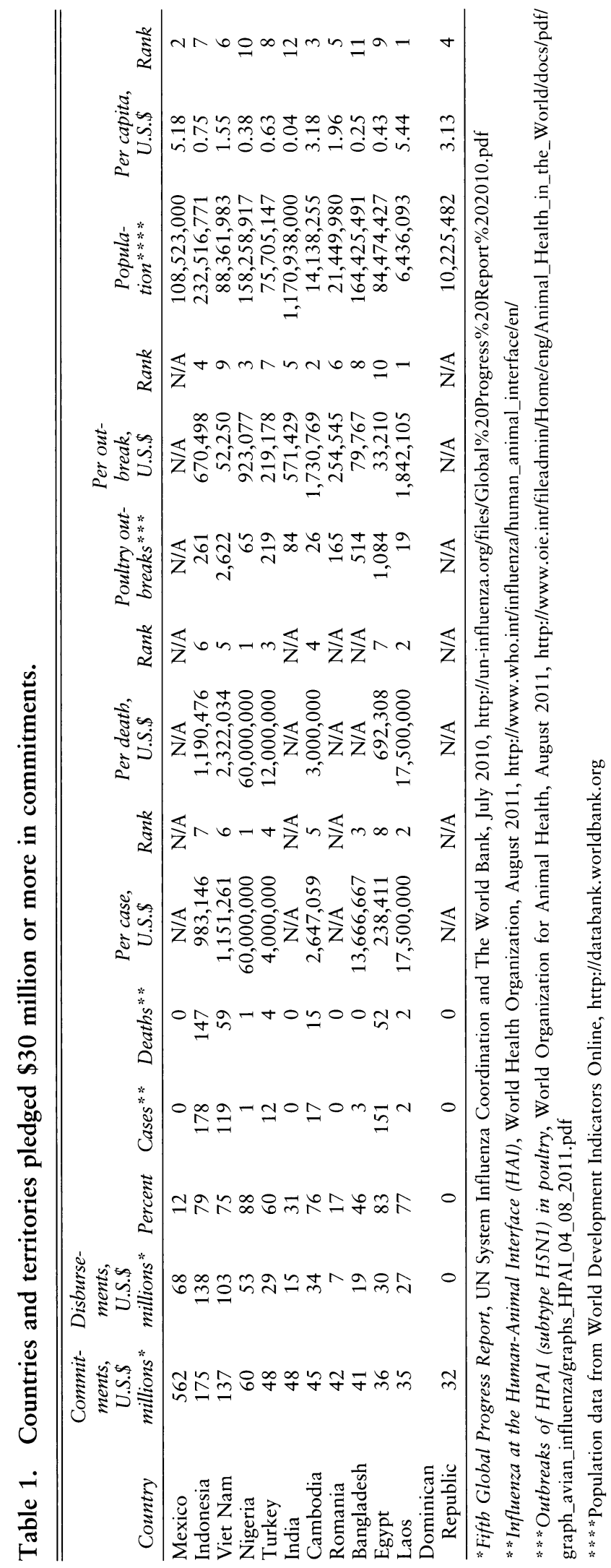




\section{Avian influenza}

Table 2. Typology of risks associated with highly pathogenic avian influenza (HPAI).

\begin{tabular}{ll}
\hline \hline $\begin{array}{l}\text { (I) The risk HPAI poses to } \\
\text { poor people's poultry. }\end{array}$ & $\begin{array}{l}\text { (II) The risk HPAI (in poor } \\
\text { people's poultry) poses to the poor } \\
\text { themselves. }\end{array}$ \\
$\begin{array}{ll}\text { (III) The risk HPAI in } \\
\text { poor people's poultry poses } \\
\text { to not-so-poor people's poultry } \\
\text { and related business interests. }\end{array}$ & $\begin{array}{l}\text { (IV) The risk HPAI-affected poor } \\
\text { initiators of a global pandemic. }\end{array}$ \\
\hline
\end{tabular}

Source: Adapted from Otte and Holst (2008).

vulnerable to other disease risks. We thus have the problem of nonaligned interests between important parties in the endeavour to manage "risks III and IV."

Indeed, Risk II refers to common poultry diseases causing perennial die-offs like Newcastle disease, which manifests itself like HPAI but does no harm to humans. Yet the concern is that this nonalignment of interests gives rise to yet a fifth risk, which they explain as follows:

The result of this for the poor is that the "cure becomes worse than the disease," giving rise to a "Risk $\mathrm{V}$," namely that keeping and marketing poultry is constrained and thereby, at least partially, removed as an activity from the livelihoods and (more ominously) subsistence food portfolios of poor people. This may be the most serious risk poor poultry keepers face from the current HPAI "crisis." On a larger scale, therefore (i.e., beyond specific biosecurity measures, compensation scales, etc.), [we] would say that, first and foremost, "pro-poor HPAI risk reduction" means preserving poultry keeping as an economic activity that remains within the reach of people with low initial endowments. ${ }^{8}$

As the Cambodian authorities provided neither compensation for culling infected poultry nor vaccines to inoculate the animals, risks I and II have been ignored (save for TV and radio advertisements about washing one's hands, quarantining new poultry, and other behavior change modifications at the individual or household level)-despite strenuous objections and pressure from the international community.

Unlike in Vietnam, the Cambodian authorities did not implement widescale vaccination-an expensive move-but chose rather to cull "backyard birds" without compensation, whereas Vietnam compensated for culling. Despite international pressure on Cambo- dia to embrace a compensation policy for culling diseased flocks, the government refused to establish such a program for its citizens. This was based, in part, on the government's negative experiences with its "guns for cash" disarmament program. The government feared cases of false reporting and the possibility of sick birds being sent across the border from Vietnam by those who would attempt to receive compensation in Cambodia. Add to that a heavy fiscal burden (albeit a burden that would have been alleviated wholly or partially by donor funds), complex logistics, and unclear evidence on the policy's effectiveness, and the government decided against compensation. Setting a compensation precedent was thought to represent a liability, and arguably, the idea of paying citizens for taking away their possessions could engender unwanted accountability issues.

As for issues of biosecurity, a single infectious dose of avian influenza from afar is enough to trigger a small marketplace epidemic, risking potential infections to market visitors and retailers. To date, this risk has not materialized in Cambodian markets. In May 2008, after observing activities in the wet market-such as the open food market where live animals are sold at Psah Orussey, a major downtown Phnom Penh market-it appeared that no biosecurity measures had been put in place, given that workers (observed firsthand) wore no gloves and, with one exception, wore no face masks of any kind. Market sellers have little incentive to take extra precautions since it can be expensive to purchase personal protective equipment and wearing gloves and masks in the marketplace may create anxiety among customers and hurt business. It is important to note, however, that biosecurity measures in a wet market encompass more than just using personal protective equipment alone; sanitary and phytosanitary (pertaining to the health of plants; especially the freedom from pests requiring quarantine) measures are crucial.

While awareness of avian influenza and personal protection measures exists in Cambodia, this awareness has not always led to changes in poultry handling. According to Ly and colleagues "most rural Cambodians still often practice at-risk poultry handling" and "family members of H5N1-infected patients, who knew about avian influenza risks, still prepared dead or sick poultry for household consumption during massive die-offs, because they observed that neighbors with the same behavior did not become sick."9 A 2007 
CEDAC report observed that, "not many rural people and poultry producers believe about [sic] the seriousness of HPAI" and, perhaps as a result, "are not willing to collaborate with the technical departments and authorities to prevent HPAI outbreaks."10 Not surprisingly, economic considerations may be driving this intransigence:

Behavior change involves comprehensive and multidisciplinary intervention, which combines risk perception communication and feasible and practical recommendations, including economic considerations. We speculate that it is hardly feasible to sustain good poultry-handling practices if access to personal protective equipment is cost prohibitive, particularly when disease occurrence poultry die-offs are common (p. 131). ${ }^{9}$

Behavior change is an important piece of the puzzle, but so too is the issue of food security. For many poor families in Cambodia, poultry and eggs are often the main (or only) animal protein source available and people will eat even infected animals when it is the only alternative.

At the international level, the focus has indeed been on what Otte and Roland-Holst identify as risk IV, the risk HPAI-affected poor people represent to humanity as initiators of a global pandemic. The evidence of this focus is the disproportionately high funding levels of risk IV in comparison to Dengue fever, for instance-a vector-borne disease that infects an estimated 50-100 million people per year and puts at risk 2.5 billion people worldwide. ${ }^{11}$ The U.S. government slashed funding for Dengue prevention 70 percent in fiscal year 2011, from $\$ 39$ million to $\$ 12$ million. ${ }^{12}$ The risk IV focus has led to the emergence of a strategy in Cambodia-massive culling of poor people's poultry without compensation-that affects the livelihood of the country's poorest citizens.

International donors' response to avian influenza can seem dramatic, particularly as compared with an unprecedented outbreak of Dengue fever in 2007. This discrepancy outraged a prominent Swiss pediatrician, Beat Richner, the founder of several hospitals in Cambodia. In 2008, 407 individuals died ${ }^{13}$ out of some 4,000 Dengue fever cases-a mortality rate of 10 percent ${ }^{14}$-compared to avian influenza's single casualty in 2007 and two casualties in 2006 (versus 158 Dengue deaths that year), ${ }^{15}$ and four casualties in 2005 (compared with 68 Dengue deaths that year). According to Richner, the Dengue epidemic of 2006 resulted in $\$ 7$ million in additional costs to his Foundation Kantha Bopha Children's Hospitals, yet "neither a member of the International Community, nor the World Health Organization responsible on the Dengue Program, nor the Cambodian Government have made any gesture of financial contributions.",16

Richner offered an explanation for the imbalance in donor funding for avian influenza compared to Dengue fever in a full-page advertisement placed in the Cambodia Daily, Cambodia's largest English-language daily newspaper, on July 26, 2006. His open letter, titled "The Dengue Disaster: A Mirror of the Hypocrisy of the Health Policy for the Poor World," mounted a scathing attack on the international community. $\mathrm{He}$ writes (verbatim):

A night in February 2007 a severely sick child arrived in Kantha Bopha from Kampong Cham Province, having been treated as typhus there three days in a so called private clinic. (Not in a health center as it was reported). Arrived in Kantha Bopha, the same night the clinical diagnosis Bird Flu was made thanks to the sophisticated facilities, thanks to the fact, that Kantha Bopha is free. The family was poor, it has lost all their poor money in the so called private clinic. If they should pay, they would not have been traveled to Kantha Bopha ..... and nobody would be aware of the Bird Flu at the Vietnamese Border in Kampong Cham Province. The child has died the same night. The next day WHO, experts and others were traveling to the child's home next to the Vietnamese border in order to neutralize the area from Bird Flu. That is ok! [Emphasis original] But to the homes of the Dengue cases nobody is traveling to. Since ever we give the addresses of the homes of all Dengue cases to the Ministry of Health, so we did it in November 2006, when the Epidemic started in Kampong Tom Province, Stung District.

But nobody was traveling to the place. Why this difference? [Emphasis original] The Bird Flu is a threat for the western world, so there is money and commitment. The Dengue is "only" a most severe threat for the local poor children. That is the hypocrisy of the health policy for the poor world by the International Community and especially the WHO in Geneva (p. 15). ${ }^{16}$

Richner's alarm is shared, in fact, by the World Health Organization, which noted that in 2007 alone, more than 


\section{Avian influenza}

890,000 cases of Dengue were reported in the Americas and that the disease is endemic to 100 countries in Africa, the Americas, countries of the Eastern Mediterranean, Southeast Asia, and Western Pacific (the latter two are the most seriously affected). ${ }^{11}$ The mortality rate from Dengue Hemorrhagic Fever, a lethal complication from Dengue, is 20 percent if untreated. If treated, this mortality rate drops to 1 percent.

\section{Avian influenza in Thailand, Indonesia, and Vietnam}

The ways Cambodia's neighbors have managed international efforts to curb avian influenza provides a useful context for examining how Cambodia leveraged avian influenza funds to prevent the spread of disease, particularly with regard to how these countries have participated in cross-border collaboration to share information and biological materials on disease outbreaks. Efforts to prevent and manage H5N1 disease include focusing on animal surveillance, vaccination, and culling and compensation. The economic effects of avian influenza in nearby Southeast Asian countries were markedly different from those found in Cambodia, however, and no two countries responded to the crisis in precisely the same manner. For example, because Cambodia's economy was heavily based on backyard poultry, all policies related to culling and compensation underwent a great deal of debate. For other nations, this issue was not necessarily of paramount concern. Social scientists Ian Scoones and Paul Forster provide an overview of some of the more salient regional variations as it pertains to culling and compensation:

For those framing the problem as an emergencyand focusing on pandemic threat to humans-mass culling of chickens is seen as a necessary evil, which if compensated for, offers a substantial public good benefit. But looked at from the perspective of those whose livelihoods at least in part depend on these poultry, such an intervention can be catastrophic. Clearly the impacts will depend on where it happens and the alternative sources of income which might be available. Banning backyard birds in Thailand, say, has less of an impact, and causes less of an uproar than it does in Vietnam or Cambodia where economic and livelihood contexts are different (p. 41). ${ }^{17}$

For a country like Thailand, the export of poultry is an important part of the economy. Vaccination, as was used in Vietnam, would render poultry unexportable due to health concerns. Therefore, Thailand's primary focus in the wake of the avian influenza outbreak has been on massive culling of the poultry flocks in order to preserve access to international markets. ${ }^{18}$ But this hits rural farmers harder than others. According to Viroj $\mathrm{Na}$ Bangchang, president and founder of the Consumer Task Force Association of Thailand, rural farmers in Thailand "don't have anything left if you kill all the chickens." ${ }^{19}$ At the same time, small-scale poultry producers, including cockfighting enthusiasts, were saddled with stricter controls and biosecurity standards. The government therefore instituted innovative strategies, such as "bird passports," to reduce the burden on small producers. ${ }^{20}$

Indonesia, whose economy holds the middle ground between Cambodia's backyard poultry and Thailand's industrial production, made efforts to overcome the epidemic, but these were hampered by ethnic differences between producers and regulators, which led to mistrust and lack of coordination. Because Indonesia is large, decentralized, and geographically sprawling, with a thriving democracy, it has been more challenging for the government to mount a centralized response, and avian influenza remains entrenched. For Indonesia, other diseases, sectarian tensions, and natural disasters all tend to overshadow the threat of avian influenza as a public health concern. Despite these obstacles, the country has instituted a policy of widescale vaccination, and a USAID program is strengthening private sector engagement in Indonesia's decision-making processes through joint workshops and training initiatives that promote the prevention, detection, and control of avian influenza.

Meanwhile, Vietnam, which does not export poultry commercially, has embraced widespread culling and vaccination of animals with compensation of as little as 10 percent of market price. ${ }^{19}$ A Food and Agriculture Organization of the United Nations case study commented on the mixed success of Vietnam's vaccination program:

Viet Nam has been practicing mass vaccination of poultry twice a year (October and April) since autumn 2005 to control epidemic of HPAI, with some considerable empirical evidence of success. However, it has been recognised that this control strategy is not sustainable over the whole country in the long term. Mass vaccination requires significant financial resources from the government and ties up human resources in the agriculture sector (p. 48). ${ }^{21}$ 
In addition to vaccination, the Vietnamese government carried out animal surveillance in 16 target provinces and cities within Vietnam. Infected farms are not regularly subjected to outbreak investigations, however, and therefore it continues to be difficult to pinpoint the ways avian influenza is spreading. Vietnam is still considered a hotspot for the disease, and the country experienced an increased number of outbreaks during 2009 compared with the previous year. While it is true that Southeast Asia is considered an originating point for avian influenza, a pandemic can originate anywhere in the world-as happened in Mexico with A/H1N1 (swine flu). Indeed, the World Health Organization has captured the geographic location of approximately 600 public health emergencies across dozens of countries over the past decade. ${ }^{22}$ Recently, such public health emergencies have mostly emerged in Africa. But, historically, the U.S. has also been susceptible to pandemic outbreaks, most notoriously with the 1918 flu pandemic (which started in the continental U.S. but became known as the "Spanish flu").

\section{Actors, networks, and interest mapping: Elite survey results}

What becomes immediately apparent in Cambodia's political economy of disease control, particularly as it concerns avian influenza, is the numerous external actors involved in a country of only 14 million people. Since the U.N.-managed elections of 1993, which brought in a plethora of NGOs, Cambodia's political terrain has been utterly transformed. Most obviously, the international community has provided billions of dollars in development aid. At least in part, the governing Cambodian People's Party has used these funds to consolidate control over rural provinces. Equally important, international intervention has enabled non-state actors to contest state authority. By invoking democracy and human rights, public health activists in Cambodia have been able to bypass the state and appeal directly to the international community in their efforts to combat avian influenza.

Lack of national ownership over the spread of H5N1 is a serious problem not just in Cambodia but throughout the developing world; indeed, a donor-driven agenda can sometimes result in a "tail wagging the dog" scenario.
The government may nominally lead public efforts at disease control by chairing a committee or convening a thematic working group, but donors can have significant influence. By some estimates more than 160 nongovernmental organizations have conducted avian influenzarelated activities in Cambodia. While it is not possible to map the interrelationships among all these NGOs entirely, Figure 1 shows the node degree ranking (the number of physical links per node) of the United Nations Resident Coordinator-recognized actors involved in avian influenza interventions. These are the most important funders and implementing partners in UNRC's view. $^{23}$ The blue dots represent country governments, while the red dots represent local NGOs.

Most notably, while more than 160 NGOs were at some point engaged in avian influenza control activities, only two were still active by 2009 . It is also immediately apparent that the U.S. government has taken a very active role in funding avian influenza activities using through USAID and US-CDC. Both agencies have six links or node degrees-more than any other entity mapped. As this interest map is based on funds and partners officially recognized by the United Nations Resident Coordinator's Office, it cannot reveal informal arrangements and interests, an important aspect of the political economy of disease control. The private sector, with firms such as CP Cambodia (a subsidiary of Thailand's Charoen Pokphand Group, a multibillion dollar conglomerate), is not represented because of the opacity of its operations in Cambodia. The author conducted extensive interviews with private sector firms, but companies would not release copies of their internal research or market strategies due to concerns about market competition.

The elite survey addressed the Cambodian government's effectiveness in managing avian influenza by asking several questions that allowed respondents to use a 5-point scale ranging from "strongly agree" to "strongly disagree." The first question directly addressed the issue of the Cambodian government's effectiveness: "With respect to avian influenza, the government intervened effectively and appropriately, given resource allocations." A majority of respondents agreed or strongly agreed that the Royal Government of Cambodia intervened effectively and appropriately to the avian influenza epidemic, given resource allocations, in terms of human prevention $(56 \%)$, animal prevention $(54 \%)$, and pandemic preparedness $(60 \%)$ (see Figure 2 ). 


\section{Avian influenza}

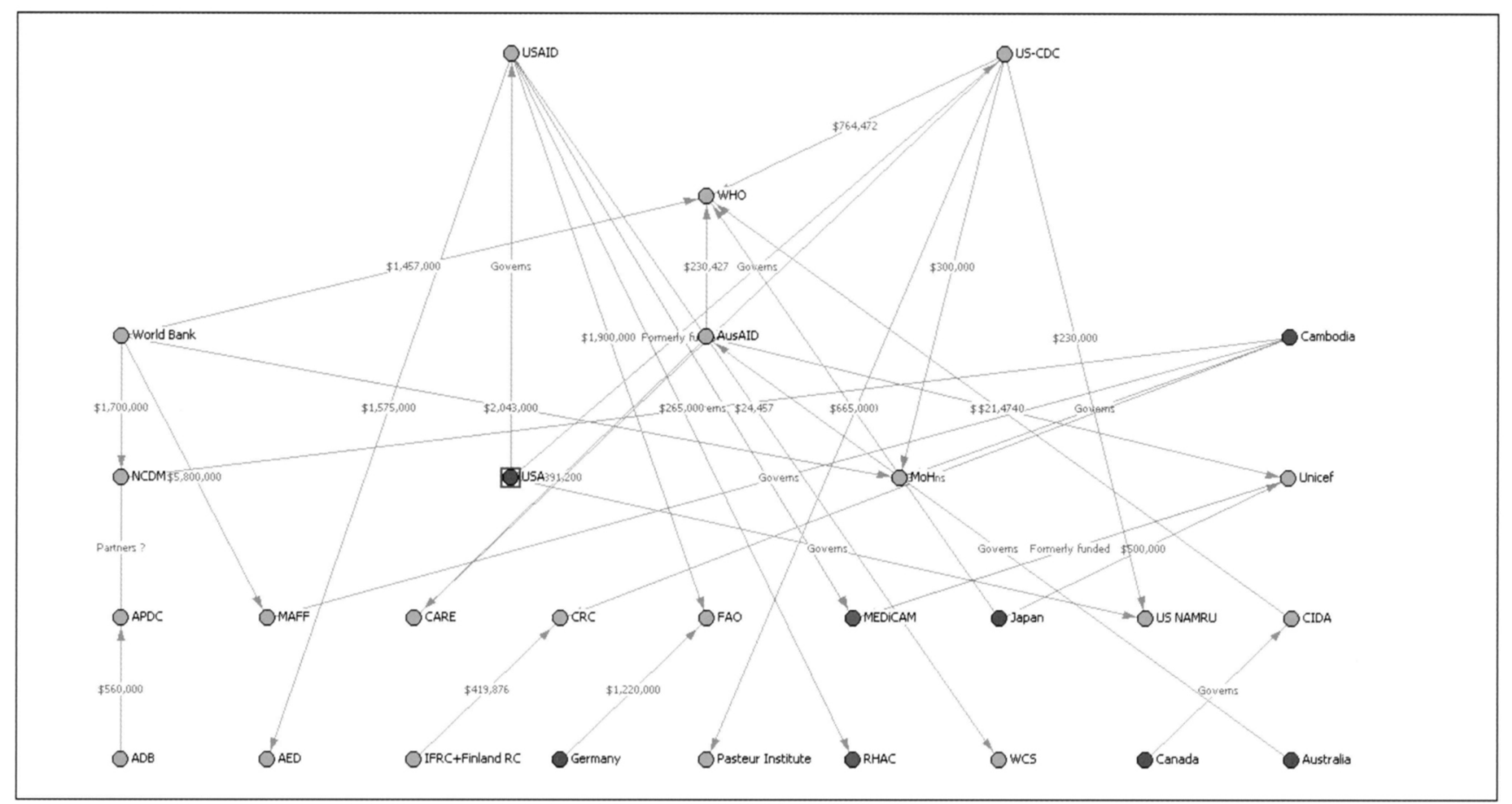

Note: Based on data from United Nations Resident Coordinator (2008). Interest map generated from author's calculations.

Figure 1. Interest mapping of funding agencies ranked by node degree.

In contrast, however, only a third of respondents agreed or mostly agreed that the government responded effectively and appropriately to protect livelihoods. Clearly, those with a professional stake in avian influenza control felt that the government's ability to protect its citizens' livelihoods was shaky at best. While one respondent felt the damage to livelihoods was limited because of the short duration of outbreaks, others were left unimpressed, remarking: "Nothing is done to take [care] of the livelihoods of the smallholders" and "No specific livelihoods intervention [occurred] that I am aware of. In fact, there is no record of any discussions on compensation for loss of poultry in the event of outbreak". The written comments on the topic of the Cambodian government's ability to protect livelihoods were among the harshest. But, this was not the only criticism. One informant was also concerned that, "Instances of suspected [cases were] not being investigated" (see Table 3).

The elite survey next addressed the effectiveness of international donors by posing the following statement: "With respect to avian influenza, donors (including all non-Royal Government of Cambodia entities whether local or international) have intervened effectively and appropriately, given resource allocations." As shown in Figure 3, donors were somewhat more positively perceived in terms of their avian influenza intervention effectiveness than the government of Cambodia. Donors, on the other hand, were rated poorly on protecting livelihoods, with only 38 percent of respondents agreeing, and none strongly agreeing that donors had effectively and appropriately intervened, given resource allocations. Only 43 percent of respondents agreed or strongly agreed that donors were effective in pandemic preparedness interventions.

The written comments in Table 4 reveal varied viewpoints toward avian influenza donor effectiveness, though the results are primarily positive. Donors were praised for paying "attention to allocate budget[s] for avian influenza" to promote prevention among humans populations and for their "good funding support" for animal prevention and pandemic preparation. Demonstrating awareness of donor constraints, one respondent wrote that, "donors wish to help the 


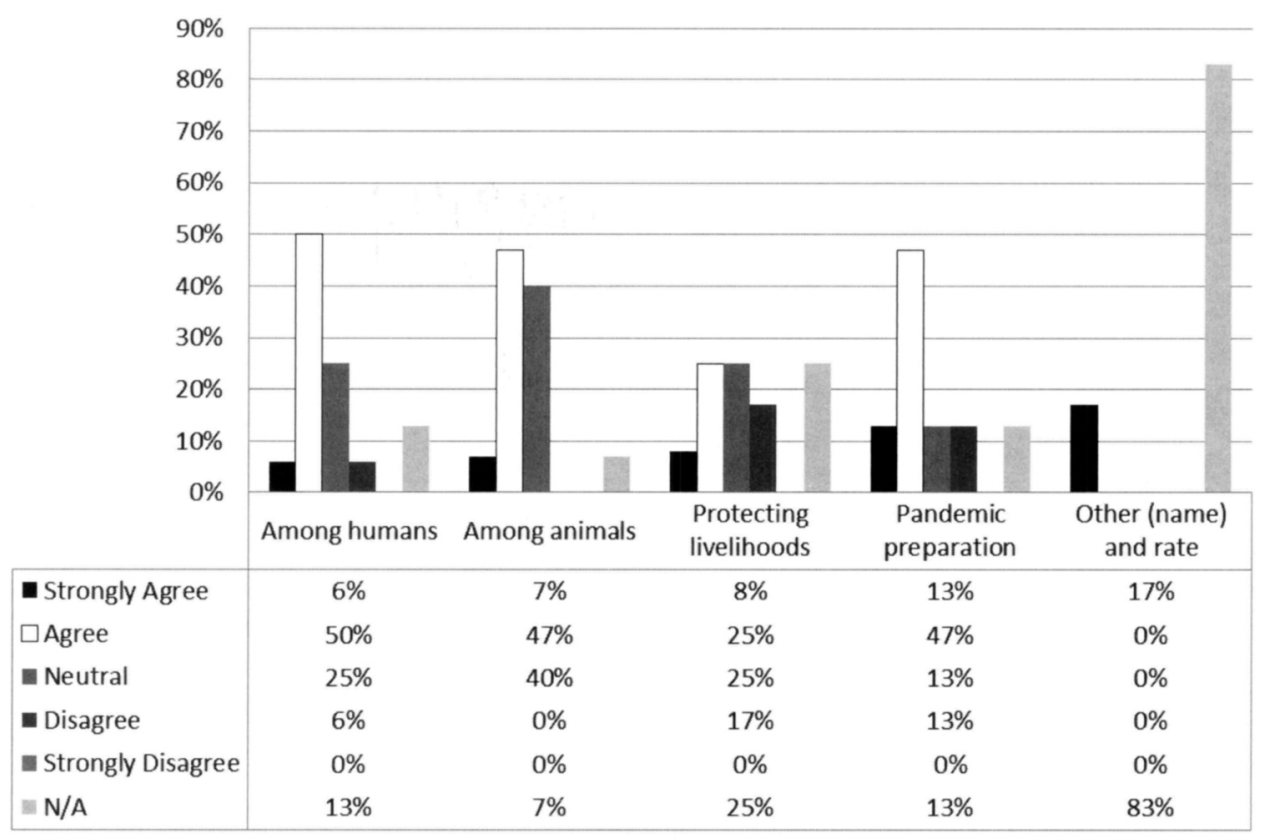

Note: Results of elite survey $(N=17)$ fielded May 27 - June 5, 2008.

Figure 2. Elite survey agreement that the Cambodian government intervened effectively in the avian influenza outbreak.

RGC to control avian influenza, but can't put any pressure on the RGC."

Notably, almost no written feedback was received on the topic of whether donors effectively protected livelihoods, except for one respondent's view that "donor support has been strong but is now coming to a close in IEC [Information, Education, and Communication] work." This was a blanket response and therefore had no special relevance. This reticence to speak to the question of livelihoods may represent a lack of willingness by respondents, particularly from the donor community, to examine the situation objectively.

Respondents were also asked to indicate specific donors or government entities they believed had been particularly successful or unsuccessful in combating avian influenza in Cambodia, specifying who is responsible and why. The Ministry of Health and its Communicable Disease Control Department were each mentioned twice as "successful," for a total of four mentions out of 16 successful entities named-twice as many as the next highest organizations: USAID and the Ministry of Agriculture, Forestry, and Fisheries. This suggests that among avian influenza stakeholders, both the Ministry of Health and its CDC Department stood out as "successful."

Some respondents provided written comments to explain why they perceived these agencies as particularly successful: "Very strong commitment from leaders-with support from the WHO, USAID and others" and "[The Ministry of Health] and their partners [have been] successful in avian influenza intervention. Avian influenza intervention went to all areas in Cambodia. As evident [sic] Cambodia has no new confirmed case since April 2007'. Following the July 2008 election, more cases were discovered-but only after the election. Another written entry named the head of the Ministry of Health's Communicable Disease Department specifically for being successful.

Respondents were much more reluctant to name unsuccessful entities. Indeed, only four organizations were named (see Table 5), each receiving one mention. Because these negative comments may reflect efforts to settle scores, these mentions are not intended to be representative, merely suggestive. 
Table 3. Stakeholder comments regarding governmental effectiveness on avian influenza

\begin{tabular}{c}
\hline Dimension \\
$\begin{array}{c}\text { Among human } \\
\text { - Ropulations }\end{array}$ \\
- has less national budget with respect to avian influenza. \\
- The human resources are very low in Cambodia. \\
- Have strong surveillance team at national and provincial levels. Currently this team [is] very active. \\
- Cambodia right now is implementing ILI [Influenza-Like Illness] survey under management of CDC of \\
Ministry of Health. \\
- Government has worked with UN agencies to prepare a response to pandemic avian influenza. \\
- While there is response by ministries such as Ministry of Health and Ministry of Education Youth and \\
Sport, the quality of the response is highly variable. Capacity of the government in the key ministries \\
is typically weak. \\
- With the support from the Government, avian influenza working groups, technical working groups have \\
been established, and response on time. \\
- The Royal Government of Cambodia doesn't put all efforts to prevent, control and [eradicate] avian \\
influenza. [They don't] want to compensate Poultry Raisers in avian influenza outbreak areas, \\
[don't] want to share the information, [don't] want to conduct a trial on the use of avian influenza \\
vaccines... etc.
\end{tabular}

Among animal $\bullet$ Regarding the disease control the interventions seems appropriate (no outbreaks reported since April populations 2007).

- The law for animal movement (local and/or international) is not really existing.

- Virtually no resource allocations have been available for wildlife surveillance. The Royal government has worked with the US government to allow us to train their forestry and agricultural personnel on wildlife surveillance. However, the Royal government has not allocated any funds for this effort.

- The Department of Animal Health and Production partners with the Food and Agriculture Organization for training of staff.

Protection of - Not being very aggressive in controlling the disease, livelihoods of most people in the country liveliboods were only little affected for a short period of time.

- Nothing is done to take [care] of the livelihoods of the smallholders.

- I am one of the population in Cambodia and I do not hear about the Govt. strategy for responding to avian influenza.

- The information, education, and communication work on behaviour change is well recognised for its quality and application. Other countries in the region and further afield have used this material and process. Good strong coordination between government, nongovernmental organizations, and UN agencies have ensured consistency in messages to the local level.

- No specific livelihoods intervention [occurred] that I am aware of. In fact, there is no record of any discussions on compensation for loss of poultry in the event of outbreak.
Pandemic - In principal, support is strong, but operational support a bit weak.
preparation - Poor pandemic preparation is tied to limited human resources
- With the technical support from the World Health Organization, National Committee for Disaster Management has now undertaken the organization [of] a pilot of provincial pandemic planning in Siem Reap. This provincial pandemic planning is participated from diverse departments: public and private sectors. This plan will be decentralized to the district level and will be a model to other provinces, then consolidated as a national pandemic plan.
- Spot on TV how to prevent in case where it happen.
- The provincial lead process is unconventional and globally a first. An excellent model that will support very strongly central pandemic planning that will start soon.
- Tbe National Committee for Disaster Management partners with the World Health Organization on pandemic planning, and an increase in activity within the last year.

\begin{tabular}{l}
\hline Other $\quad$ Cambodia has good model of partnership among stakeholders in avian influenza response. \\
Note: Open ended responses from elite survey. Selected written comments edited only for clarity (not grammar).
\end{tabular} 


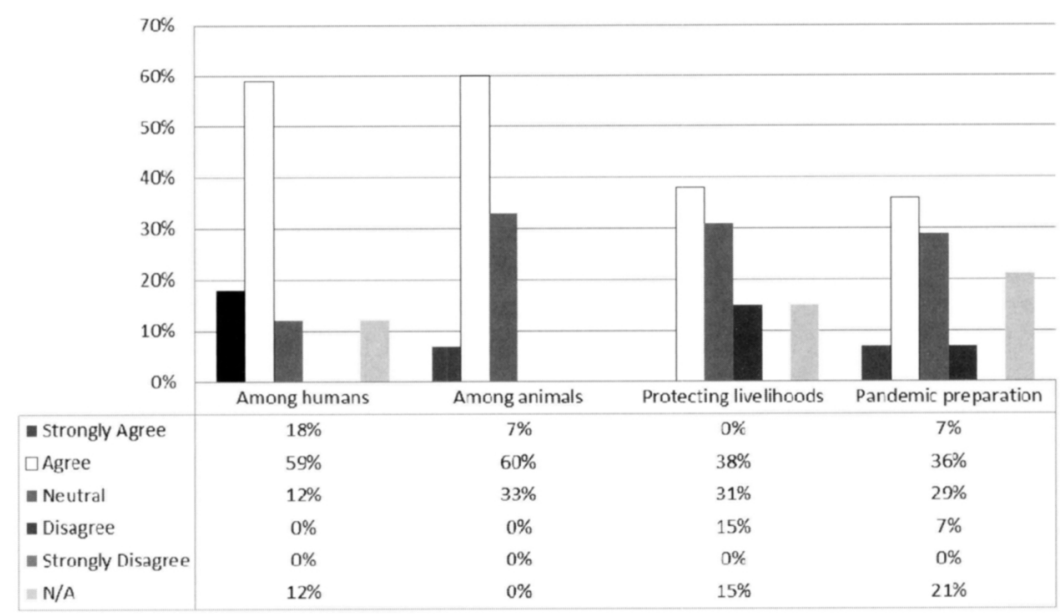

Note: Results of elite survey $(N=17)$ fielded May 27 - June 5, 2008.

Figure 3. Elite survey agreement that donor organizations intervened effectively and appropriately in the Cambodian avian influenza outbreak.

The elite survey also posed a question about whether Cambodia's preparedness and surveillance (both active and passive) for an avian influenza-like disease has improved over time. Passive surveillance involves medical care providers reporting notifiable diseases to government agencies based upon a published list of conditions on a case-by-case basis. Active surveillance goes beyond this with syndromes (such as influenzalike illness in the form of sudden onset of fever, cough or sore throat or running nose, and no other cause identified for the disease) collected in aggregate form on a standardized schedule via regular outreach from government agencies (pp. 7, 9). ${ }^{24}$ Respondents were in agreement that Cambodia's preparedness and surveillance, both active and passive forms, were in a better position today than when they had first begun work in Cambodia (see Figure 4).

While field visits took place in 2008, and deaths from avian influenza tapered off in 2009 and 2010, the number of deaths in Cambodia increased 70 percent in the first seven months of 2011, suggesting that disease control efforts have not kept up despite the continuing and perhaps growing risk of infection. Alternatively, it may be that improved reporting efforts have borne fruit and this accounts for why so many new cases have emerged. Of course, the goal remains disease control, surveillance, and detection prior to irreparable human harm. The deaths in all seven cases in 2011 suggest that surveillance and detection efforts in Cambodia have failed to contain the disease. Worldwide, the number of confirmed human cases of H5N1 in 2009 was almost double that of 2008. These developments require further investigation and monitoring to gain a more comprehensive understanding of avian influenza's continued spread throughout Cambodia, Southeast Asia, and the world.

\section{Conclusion}

A number of lessons emerge from this case study analysis. First, the interests of the citizens of Cambodia, the Cambodian government, and the international donor community are not well synchronized when it comes to avian influenza preparedness and prevention. Greater government-donor coordination is needed to align individual and national interests with the parties of international aid organizations. Second, the ability of the government and donor agencies to protect the livelihoods of the Cambodian people cannot be assumed, as responses suggest neither the government nor donors were particularly effective in this area. Third, donor organizations and Cambodian government agencies are not perceived as 


\section{Avian influenza}

Table 4. Stakeholder comments regarding donor effectiveness in combating avian influenza

\begin{tabular}{|c|c|}
\hline Dimension & Stakeholder comments \\
\hline $\begin{array}{l}\text { Among } \\
\text { buman } \\
\text { populations }\end{array}$ & $\begin{array}{l}\text { - All donors paid attention to allocate budget[s] for avian influenza. } \\
\text { - Very good funding support. } \\
\text { - I [want to say] yes and no. YES because the organizations are working in avian influenza are } \\
\text { doing their best; and NO because I afraid the donors try to forget the problem and I think we still } \\
\text { have to work on it and to be careful. } \\
\text { - Fairly good collaboration at implementation level. } \\
\text { - I see many int'l nongovernmental organizations have set up the avian influenza projects or } \\
\text { activities and spent a lot of money on advocacy and mobilization. } \\
\text { - Donors was strongly support and response quickly to any human outbreak and all kind of } \\
\text { communication. } \\
\text { - Donor support to human health is noted. Consistency beyond the perceived emergency period will } \\
\text { be more of a challenge but is necessary particularly with regard to pandemic planning. }\end{array}$ \\
\hline $\begin{array}{l}\text { Among } \\
\quad \text { animal } \\
\text { populations }\end{array}$ & $\begin{array}{l}\text { - As long as my organisation is concerned, the donor intervention is ok. I have no overview of } \\
\text { other agencies. } \\
\text { - Good funding support. } \\
\text { - When we have no enough resource (financial and human) it is difficult. } \\
\text { - Donors wish to help the RGC [Royal Government of Cambodia] to control avian influenza, but } \\
\text { can't put any pressure on the RGC. }\end{array}$ \\
\hline $\begin{array}{l}\text { Protection of } \\
\quad \text { livelihoods }\end{array}$ & $\begin{array}{l}\text { - Donor support has been strong but is now coming to a close in information, education, and } \\
\text { communication work. }\end{array}$ \\
\hline $\begin{array}{l}\text { Pandemic } \\
\text { preparation }\end{array}$ & $\begin{array}{l}\text { - Cambodia has multisectoral response/stakeholders. } \\
\text { - Good funding support. } \\
\text { - The process of funding is a bit late. } \\
\text { - I haven't seen any int'l nongovernmental organizations has activities on the Pandemic } \\
\text { preparation. } \\
\text { - Donor support has been good however very strong and longer term support is needed for multi } \\
\text { sectoral planning. Particular attention is needed to understand the parallel process of both central } \\
\text { level pandemic planning and provincial level. The central level work will soon receive support but } \\
\text { will need capacity development support, and the provincial process will soon run out of financial } \\
\text { support. The pilot will be complete but the roll out needs support to truly inform central level } \\
\text { planning. and increase resilience to shocks at the local level. }\end{array}$ \\
\hline
\end{tabular}

Note: Open ended responses from elite survey. Selected written comments edited only for clarity (not grammar).

equally effective. To wit: there was a sizeable contrast between the Ministry of Agriculture, Forestry, and Fisheries and the Ministry of Health in how each was perceived in terms of pandemic prevention and preparedness. In short, progress made to date by Cambodia is precarious. While it is generally positive, it is only marginally so. Clearly, more work needs to be done to prevent the spread of avian influenza in the future.

To this point, this study reveals key challenges, obstacles, and opportunities for responding to avian influenza and other emerging global epidemics. It has investigated the policies put in place to respond to avian influenza in Cambodia, identifying key actors, networks, and conflicting priorities. Based on this analysis, some of the most important lessons learned in Cambodia are as follows:

- Pervasive institutional failures, including poor governance and lack of political commitment, have plagued the political economy of disease control in Cambodia. These failures are by no means limited to avian influenza alone but exhibited themselves richly in the narratives explored.

- Scant information is available to share for government authorities to assess the effectiveness of various policy alternatives (e.g., compensation for culling). How effective is compensation when used elsewhere, and particularly in countries neighboring Cambodia? 
Table 5. Stakeholder comments about "unsuccessful" entities.

\begin{tabular}{|c|c|}
\hline Entity & Stakeholder comments \\
\hline $\begin{array}{l}\text { Food and } \\
\text { Agriculture } \\
\text { Organization }\end{array}$ & $\begin{array}{l}\text { - Can not work closely with the NaVRI } \\
\text { [National Veterinary Research } \\
\text { Institute] Cannot get the real results. } \\
\text { Does not want to cooperate and } \\
\text { collaborate with other International } \\
\text { Agencies...etc. Does not want to } \\
\text { involve other International Agencies in } \\
\text { AI activities. }\end{array}$ \\
\hline $\begin{array}{c}\text { Ministry of } \\
\text { Health }\end{array}$ & $\begin{array}{l}\text { - Has question of sustainability. Because } \\
\text { of now depending on donor funds. In } \\
\text { addition, AI message at community level } \\
\text { are limited. }\end{array}$ \\
\hline USAID & $\begin{array}{l}\text { - Good big funding giving to many } \\
\text { NGOs, but some activities seem not } \\
\text { clear, some are overlapping. }\end{array}$ \\
\hline $\begin{array}{l}\text { Wildlife } \\
\text { Conser- } \\
\text { vation } \\
\text { Society }\end{array}$ & $\begin{array}{l}\text { This organization does not work with } \\
\text { the government veterinary and wildlife } \\
\text { professionals. Instead, they conduct } \\
\text { surveillance on their own, often } \\
\text { providing little information to the } \\
\text { veterinary and wildlife officials. The } \\
\text { organization should focus on training } \\
\text { and empowering Royal Government } \\
\text { wildlife and veterinary professionals to } \\
\text { establish a wildlife surveillance system } \\
\text { within Cambodia. Through well- } \\
\text { designed and coordinated training } \\
\text { efforts, the government will develop } \\
\text { the capacity to continue surveillance } \\
\text { after NGO expertise leaves Cambodia. }\end{array}$ \\
\hline
\end{tabular}

Note: Open ended responses from elite survey. Selected written comments edited only for clarity (not grammar).

Without access to data on the effectiveness of compensation, the Cambodian government was able to dismiss the notion. Making this information more readily available to government agencies would help in the control of diseases like H5N1.

- Authorities are not willing to commit their own funds but are prepared to accept donor funds to keep avian influenza and pandemic preparedness programs going in the near term. However, successful approaches often cease as soon as the flow of donor money dries up, a growing concern given the current precarious state of global economies.

- Donor activities in Cambodia have been overtly focused on detecting and preventing the spread of avian influenza threats to donor countries themselves, but this approach does not align well with Cambodia's need to protect livelihoods.

- Whether rightly or wrongly, Cambodians and their government perceive the risks posed by avian influenza to be low. This is true despite the fact that Cambodia's Ministry of Health has announced seven confirmed Avian flu-related deaths in 2011 alone, along with reports of poultry die-off. As of this writing, 17 people (in total) have become infected with the H5N1 virus in Cambodia and 15 have died from complications of the disease.

A key priority for Cambodia will be capacity building. Developing effective surveillance systems cannot be an exclusively technical exercise, and sending equipment and reagents (substances used for chemical reactions, especially for chemical synthesis and analysis) ${ }^{25}$ to Cambodia, or training lab staff in their use on study missions are a necessary but not sufficient actions to control the disease. Capacity building can take decades. Using volunteer lab staff from overseas might be an effective intermediate solution to bridge the gap in capacity until reform of the country's civil service and political economy of disease control can take place. In addition, donors and the Cambodian government need to give more consideration to each other's interests. Donors need to move away from funding numerous, sparsely populated laboratories where little to no diagnosis actually takes place due to lack of capacity or manpower, in an effort to build capacity in the area of infectious disease diagnosis. Funding will likely be more effective when the focus is on quality of biomedical diagnosis instead-fewer labs that function at a high level.

At the same time, ultimate responsibility for the success or failure of policies in Cambodia must rest with those in charge, that is, the authorities themselves. While there has been some progress in pandemic preparedness in Cambodia since the outbreak of avian influenza in 2004, government and donor interventions have not yet proven successful in detecting and preventing the spread of avian influenza. Prior to 2011, Cambodia had only 10 confirmed cases of H5N1. Since 2011, seven new confirmed cases of avian influenza have emerged in country, and all of these have been fatal. On a global level, the number of countries exposed to avian influenza since 2003 also continues to rise-the current total stands at 63 


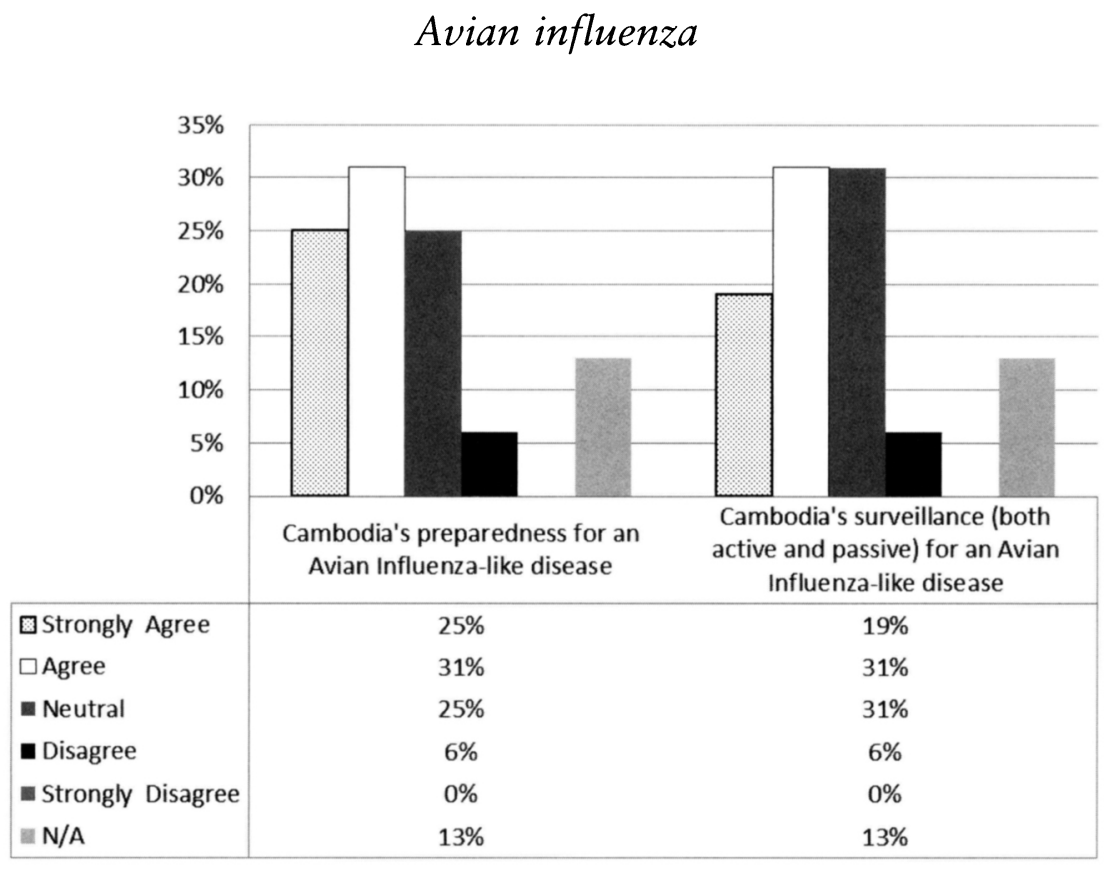

Note: Results of elite survey $(N=17)$ fielded May 27 - June 5, 2008.

Figure 4. Elite survey agreement that Cambodia's preparedness for an avian influenza-like disease has improved significantly.

nations-and the disease has reemerged in several countries where it was believed to have been eliminated. It is imperative that the public health community absorb lessons learned from vulnerable countries such as Cambodia to help prevent the further global spread of emerging infectious diseases like H5N1.

\section{Note}

Dr. Sophal Ear is Assistant Professor of National Security Affairs at the U.S. Naval Postgraduate School where he teaches courses on post-conflict reconstruction and political economy. $\mathrm{He}$ also serves as Vice Chair of the Diagnostic Microbiology Development Program, a nonprofit that builds capacity for reliable infectious diseases diagnosis in the developing world. A graduate of UC Berkeley and Princeton University, he moved to the United States from France as a Cambodian refugee at the age of 10 .

Funding for the research contained in this paper was provided through the STEPS Centre of the University of Sussex from the Food and Agriculture Organization's ProPoor Livestock Policy Initiative, the UK Department for International Development-funded Pro-Poor Risk Reduction project and the Livestock-sector governance in developing countries project coordinated by Chatham House, London with support from DFID and the World Bank. Thanks to anonymous referees, Erik Bucy, Nicoline De Haan, Ian Scoones, Sigfrido Burgos, Leslie Kriesel, Amy Strong, and Sarah Davis for comments and help. Excellent research assistance was provided by Linda Tauch, Pete Pin, Vannarith Chbeang, Sopheary Ou, Chhorvivoinn Sumsethi, and Jim Chbor. Most of all, I thank the nearly 50 interviewees willing to speak to me during my three visits to Cambodia. The views expressed in this article are mine alone and do not reflect the views of the Department of the Navy, the Department of Defense, or the U.S. Government.

\section{References}

1. "Chinese hesitancy on avian flu," Nature, January 26, 2006, 439: 369.

2. Dennis Normile, "First human case in Cambodia highlights surveillance shortcomings," Science, February 18, 2005, 307: 1027.

3. James Hookway, "Bad diagnosis: In rural cambodia, avian influenza finds a weak spot; human cases escape notice amid ignorance, poverty as a pandemic threatens; advice: Dont eat sick birds," The Wall Street Journal, March 4, 2005, A1. 
4. World Development Indicators, http://databank. worldbank.org, accessed August 12, 2011.

5. World Bank, "Avian and human influenza: Financing needs and gaps," 2006, http://siteresources.worldbank.org/ PROJECTS/Resources/40940-1136754783560/

AHIFinancingGAPSFINAL.pdf, accessed August 12, 2011.

6. UN System Influenza Coordination and The World Bank, Animal and pandemic influenza: A framework for sustaining momentum, Fifth Global Progress Report, July 2010, http:// un-influenza.org/files/Global\%20Progress \%20Report \% 202010.pdf, accessed 12 August 2011.

7. Charlene Porter, "Health officials focus on how to respond to disease outbreak: United States backs training in Thailand; Indonesia reports more human bird flu," The Washington File, Bureau of International Information Programs, U.S. Department of State, July 21, 2006.

8. Joachim Otte and David Roland-Holst, "RE: [Pro-Poor Risk Reduction Case studies] E-Consultation Discussion...Risk," e-mail communication from Joachim Otte to author and other e-consultants, August 20, 2008, 9:37 PM.

9. Sowath Ly, Maria D. Van Kerkhove, Davun Holl, Yves Froehlich, and Sirenda Vong, "Dispatches: Interaction between humans and poultry, rural Cambodia," Emerging Infectious Diseases, 2007, 13(1): 130-132.

10. Community Economic Development Assistance Corporation, "Rural Livelihood and Biosecurity of Gender and Socio-economic Impacts of HPAI and Its Control Over Rural Livelihoods and Bio-Security of Smallholder Poultry Producers and Poultry Value Chain in Cambodia," Executive Summary, Centre d'Etude et de Développement Agricole Cambodgien, 2007.

11. World Health Organization, "Dengue and severe dengue," Fact sheet No.117, January 2012, http://www.who. int/mediacentre/factsheets/fs117/en, accessed March 6, 2012.

12. A. Desiree LaBeaud and Serap Aksoy, "Neglected funding for vector-borne diseases: A near miss this time, a possible disaster the next time," PLoS Negl Trop Dis, 2010, 4(10): e847.

13. Leakhana Khoun, "Child dengue deaths down but mortality rate up in 2008," The Mekong Times, June 25, 2008, http://ki-media.blogspot.com/2008/06/ child-dengue-deaths-down-but-mortality.html, accessed August 12, 2011.

14. "Dengue death rate reaches $10 \%$ in Cambodia in 2007," Xinhua News, January 4, 2008, http://news.xinhuanet.com/ english/2008-01/04/content_7365534.htm, accessed August 12, 2011.

15. "Dengue death toll surpasses all in 2006 in Cambodia," www.chinaview.cn, July 10, 2007, http:// www.oudam.com/cambodia/dengue-death-toll-surpassesall-in-2006-in-cambodia.html, accessed August 12, 2011.

16. Beat Richner, "The dengue disaster: A mirror of the hypocrisy of the health policy for the poor world," The Cambodia Daily, July 27, 2007, p. 15, http://www. beat-richner.ch/images/CambiodiaDaily_Richner2777.jpg, accessed August 12, 2011.

17. Ian Scoones and Paul Forster, "The international response to highly pathogenic avian influenza: Science, policy, and politics," 2008, STEPS Working Paper 10, Brighton, UK: STEPS Centre, http://www.steps-centre.org/ PDFs/Avian \%20flu \%20final\%20w\%20cover.pdf, accessed August 12, 2011.

18. Sophal Ear, "Cambodia's victim zero: Global and national responses to highly pathogenic avian influenza," 2009, STEPS Working Paper 16, Brighton, UK: STEPS Centre, http://www.steps-centre.org/PDFs/ Cambodia\%20new.pdf, accessed August 12, 2011.

19. Keith Bradsher, "Governments across southeast Asia work to contain bird flu," New York Times, January 26, 2004, A3.

20. Rachel Safman, "The political economy of avian influenza in Thailand," 2009, STEPS Working Paper 18, Brighton, UK: STEPS Centre, Centre, http://www. steps-centre.org/PDFs/Thailand.pdf, accessed December 8, 2011.

21. Case Study 3-1: Gathering Evidence for a Transitional Strategy (GETS) for HPAI HSN1 vaccination in Viet Nam, Food and Agriculture Organization (FAO) of the United Nations.

22. A Safer Future: Global Public Health Security in the 21st Century, World Health Report, World Health Organization,. 2007.

23. United Nations Resident Coordinator, "Avian influenza and pandemic preparedness funding matrix, Cambodia, 2008-2009,"' 2008, http://un-influenza.org/files/asia_ pacific/resource_guide/009_06_AI\%20funding\%20matrix_ Cambodia.pdf, accessed March 6, 2012.

24. Missouri Department of Health and Senior Services, "Surveillance: Bioterrorism epidemiology" Module 11, adapted from material created by Daryl Roberts, 2004, http://bioterrorism.slu.edu/bt/products/bio_epi/ scripts/mod11.pdf, accessed December 8, 2011.

25. Collins English Dictionary - Complete and Unabridged (New York: HarperCollins Publishers, 2003). 


\section{Avian influenza}

\section{Appendix \\ List of stakeholders interviewed}

The below stakeholder titles have been generalized to prevent identification of interviewees. For example, several interviewees were heads of trade associations, which would make their identities obvious. Also, government officials do not have their ministries listed for the same reason. Each stakeholder has been randomly assigned a letter to denote occupational role, status, or expertise.

- Veterinarian and consultant

- Veterinarian

- Economist

- International organization senior officer

- Avian influenza expert

- Avian influenza expert

- International organization veterinarian

- Vice president, agribusiness

- International organization officers

- Livestock expert

- Avian influenza expert

- Avian influenza expert

- Avian influenza expert

- Avian influenza expert

- NGO doctor

- Donor staff

- Donor staff

- NGO and international organization doctor

- International organization staff
- Wet market seller

- Embassy staff

- Health expert

- Education expert

- Avian influenza expert

- Health expert

- Donor management

- Embassy staff

- Avian influenza expert

- NGO management

- Livestock expert

- Donor staff

- Donor staff and doctor

- Government official

- Provincial veterinarian

- Senior government official

- Livestock expert

- NGO staff

- Avian influenza expert

- Avian influenza expert

- Farmer

- Government official

- NGO representative

- NGO representative

- Travel agency owner

- Member of Parliament

- Sister of member of Parliament

- Entrepreneur and former Secretary of State

- Civil servant employee

- Adviser 